Check for updates

Cite this: RSC Adv., 2021, 11, 39503

\title{
Ammonium-to-sodium ion-exchange process at the interlayer of octacalcium phosphate $\uparrow$
}

\author{
Yuki Sugiura, (D) * Yoji Makita and Masanori Horie (D) \\ Octacalcium phosphate (OCP) has been considered as the layer component of calcium phosphate, but \\ whether it achieves the ionic-exchange ability of conventional layer components is unclear. As OCP is \\ highly biocompatible, understanding its ionic-exchange properties would potentially expand its \\ pharmaceutical and medical applications. Herein, we demonstrate that the substituted cations in \\ ammonium $\left(\mathrm{NH}_{4}\right)$-substituted octacalcium phosphate $\left(\mathrm{OCP}-\mathrm{NH}_{4}\right)$ and sodium $(\mathrm{Na})$-containing \\ ammonium phosphate solutions undergo ion exchanges with OCP interlayers. Replacing $\mathrm{NH}_{4}{ }^{+}$with $\mathrm{Na}^{+}$ \\ did not alter the crystal structure of OCP, confirming that a substituted cation exchange process similar \\ to that in other layered compounds occurs in OCP.
}

Received 28th October 2021

Accepted 4th December 2021

DOI: $10.1039 / \mathrm{d} 1 \mathrm{ra07939e}$

rsc.li/rsc-advances

materials such as clay minerals and micas (Scheme 1). ${ }^{17-20}$ In

\section{Introduction}

Octacalcium phosphate [OCP: $\left.\mathrm{Ca}_{8} \mathrm{H}_{2}\left(\mathrm{PO}_{4}\right)_{6} \cdot 5 \mathrm{H}_{2} \mathrm{O}\right]$ is an attractive material in biomedical applications because its components-calcium $(\mathrm{Ca})$, phosphate $\left(\mathrm{PO}_{4}\right)$, and water $\left(\mathrm{H}_{2} \mathrm{O}\right)$ - are partially found in biological tissues and especially in bone. ${ }^{1-3}$ OCP has a layered crystal structure with relatively high stability and low environmental loading. Moreover, multiple ions and molecules, such as cations, dicarboxylates, and tris(hydroxymethyl)amino methane, can be substituted into precipitating OCP crystals without changing their crystallinity or crystal structure., ${ }^{1,-10}$ These guest ions and molecules are mainly substituted in the hydrous layer of OCP, where they displace the $\mathrm{Ca}, \mathrm{PO}_{4}$, and $\mathrm{H}_{2} \mathrm{O}$ constituents. ${ }^{4,11-13}$ In our previous studies on cation substitution under weakly basic solutions, we found that monovalent cations such as alkali metal ions and silver (mixture of states of $\mathrm{Ag}^{0}$ and $\mathrm{Ag}^{+}$) were substituted at the conjugated sites of $\mathrm{P}_{5} \mathrm{PO}_{4}$, the root of the hydrous layer of OCP. When OCP was synthesized in the presence of $\mathrm{NH}_{4}$ and $\mathrm{Na}$, the $\mathrm{Na}$ ions (rather than $\mathrm{NH}_{4}$ ) were preferentially substituted because their ionic radius is similar to that of $\mathrm{Ca}\left(\mathrm{Na}^{+}: 0.102 \mathrm{~nm}, \mathrm{NH}_{4}^{+}: 0.175 \mathrm{~nm}\right.$, $\left.\mathrm{Ca}^{2+}: 0.100 \mathrm{~nm}\right){ }^{14-16}$

Many examples of coexisting ions and molecules being substituted into the OCP unit lattice during the precipitation process have been reported. However, the process by which ions or molecules are substituted into the OCP unit lattice remains unknown. Considering the OCP crystal structure, the ionexchange process of guest ions substituted in the interlayers of the OCP unit lattice probably mimics that of other layered

Health and Medical Research Institute, National Institute of Advanced Industrial Science and Technology (AIST), 2217-14, Hayashi-cho, Takamatsu, Kagawa, Japan, 761-0395. E-mail: yuki-sugiura@aist.go.jp

$\dagger$ Electronic supplementary information (ESI) available. See DOI: 10.1039/d1ra07939e a case study of ammonium-substituted OCP $\left(\mathrm{OCP}-\mathrm{NH}_{4}\right)$ and Nacontaining solutions, the present study examines the ionicexchange process of guest ions substituted in the interlayers of OCP.

\section{Materials and methods}

\section{Preparation of OCP-NH}

All reagents were purchased from FUJIFILM Wako Pure Chemical Industry Inc., Japan. The preparation method of OCP$\mathrm{NH}_{4}$ was described in ref. 21. Briefly, $12.5 \mathrm{~g}$ monocalcium (a)

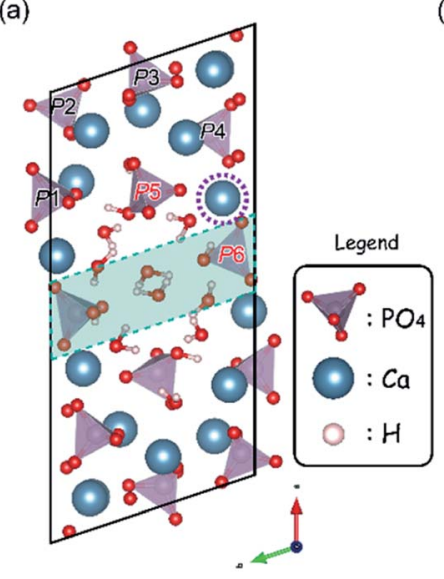

(b)

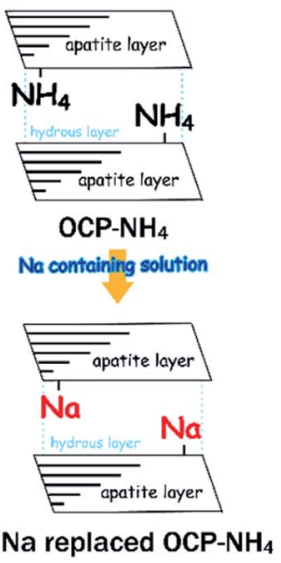

Scheme 1 (a) Schematic of the OCP unit lattice-oriented toward the $c$-axis. The phosphate $\left(\mathrm{PO}_{4}\right)$ groups are labeled $\mathrm{P} 1-\mathrm{P} 4$ and the green band highlights the hydrous layer. Purple broken-circled $\mathrm{Ca}$ indicates the replacement sites. (b) Schematics of the ion-exchange process of $\mathrm{NH}_{4}$ to $\mathrm{Na}$ in the OCP unit lattice. 
hydrogen phosphate monohydrate [MCPM: $\mathrm{Ca}\left(\mathrm{H}_{2} \mathrm{PO}_{4}\right)_{2} \cdot \mathrm{H}_{2} \mathrm{O}$ ] was immersed in $1 \mathrm{~L}$ of $1 \mathrm{~mol} \mathrm{~L}^{-1}$ diammonium hydrogen phosphate $\left(\left(\mathrm{NH}_{4}\right)_{2} \mathrm{HPO}_{4}\right)$ solution for three days at $40{ }^{\circ} \mathrm{C}$. The treated samples were washed with distilled water several times, then dried in a dry oven at $40{ }^{\circ} \mathrm{C}$ overnight.

The reference material was OCP-Na, a conventional OCP formed under weak basic phosphate solutions as described in ref. 15. Briefly, $2.39 \mathrm{~g}$ calcium hydrogen phosphate dihydrate [DCPD: $\mathrm{CaHPO}_{4} \cdot 2 \mathrm{H}_{2} \mathrm{O}$ ] was immersed in $20 \mathrm{~mL}$ of $1 \mathrm{~mol} \mathrm{~L}^{-1}$ disodium hydrogen phosphate $\left(\mathrm{Na}_{2} \mathrm{HPO}_{4}\right)$ solution for 1 day at $60{ }^{\circ} \mathrm{C}$. The treated samples were washed with distilled water several times, then dried in a dry oven at $40{ }^{\circ} \mathrm{C}$ overnight.

\section{Ion-exchange experiment of OCP- $\mathrm{NH}_{4}$}

The fabricated $\mathrm{OCP}-\mathrm{NH}_{4}(0.4 \mathrm{~g})$ was immersed in $40 \mathrm{~mL}$ of $1 \mathrm{~mol} \mathrm{~L}^{-1}\left(\mathrm{NH}_{4}\right)_{2} \mathrm{HPO}_{4}$ and $0-5 \mathrm{~mol} \mathrm{~L}^{-1}$ sodium nitrate $\left(\mathrm{NaNO}_{3}\right)$ solution placed in $50 \mathrm{~mL}$ polypropylene centrifugation tubes at $40{ }^{\circ} \mathrm{C}$. After closely packing, the vessels were shaked for 3 days at $150 \mathrm{rpm}$ and $40{ }^{\circ} \mathrm{C}$ in a thermostatic shaker (Bioshaker BR23FP, Taitec Co., Japan).

The $\mathrm{pH}$ values of the suspensions were measured using a $\mathrm{pH}$ electrode (LAQUA ToupH 9615S-10D) connected to a $\mathrm{pH}$ meter (Horiba Co. D-72, Kyoto, Japan). The samples were then washed several times with distilled water to remove any residual immersion solution before being dried in a $40{ }^{\circ} \mathrm{C}$ oven overnight.

\section{Characterization}

The crystallographic information of the samples was obtained in an X-ray diffraction (XRD) analysis (MiniFlex600, Rigaku Co., Japan) at an acceleration voltage and amplitude of 40 and $15 \mathrm{kV}$, respectively. The diffraction angle was continuously scanned over $2 \theta$ values ranging from $3^{\circ}$ to $70^{\circ}$ at a scanning rate of $5^{\circ} \min ^{-1}$ for characterization and from $2^{\circ}$ to $12^{\circ}$ at $1^{\circ} \mathrm{min}^{-1}$ for crystallographic parameter analysis.

The chemical bonding scheme of the samples was characterized through Fourier transform infrared spectroscopy (FT-IR: Nicolet NEXUS670, Thermofisher Scientific Co., USA) using a triglycine sulfate detector (32 scans, resolution $2 \mathrm{~cm}^{-1}$ ) with an attenuated total-reflection GeSe prism. All measurements were conducted in the atmosphere.

After dissolving the samples in $2 \% \mathrm{HNO}_{3}$ solution, the Ca, $\mathrm{P}\left(\mathrm{PO}_{4}\right)$, and $\mathrm{Na}$ concentrations in the samples were determined using inductively coupled plasma atomic emission spectroscopy (ICP-OES: 5110VDV, Agilent Technology Co., Japan).

\section{Results and discussion}

The main aim of this study was to investigate the ionicexchange phenomena of $\mathrm{NH}_{4}$ and $\mathrm{Na}$ in OCP crystals. Both the initial and final phases were required to be OCP. When OCP is immersed in aqueous solutions, it may convert to other phases such as hydroxyapatite [HAp: $\left.\mathrm{Ca}_{10}\left(\mathrm{PO}_{4}\right)_{6}(\mathrm{OH})_{2}\right]$ and/or DCPD via different phase-conversion processes such as dissolution and precipitation reactions. The dissolution and precipitation kinetics are mainly controlled by the ionic products and solubilities of the samples. The solubility difference between OCP and HAp was minimized under weak basic conditions. In addition, coexisting $\mathrm{Ca}$ and/or $\mathrm{PO}_{4}$ in the solution reduced the dissolving reaction of OCP, consistent with the ionic product hypothesis. We thus chose a weakly basic $\mathrm{PO}_{4}$ solution $\left(1 \mathrm{~mol} \mathrm{~L}^{-1}\left(\mathrm{NH}_{4}\right)_{2} \mathrm{HPO}_{4}\right)$ as the reaction solution.

The $\mathrm{pH}$ value of the reacting solution mainly determined the process of the reaction. Fig. 1 plots the initial and final $\mathrm{pH}$ values of the reacting solutions as functions of Na concentration. Although both the initial and final $\mathrm{pH}$ values decreased slightly with increasing Na concentration, they remained in the weakly basic region.

The most important factors of the OCP ionic-exchange process are the phases during the reactions. In this study, the phases were determined by XRD. Fig. 2 shows the wide-range XRD patterns of the samples. At all Na concentrations, the treated samples were monophasic OCP with no HAp or DCPD phases. The crystallographic phenomena in the OCP unit lattice were then subjected to further evaluation.

The behavior of $\mathrm{NH}_{4}$-substituted OCP was easily detected as an extra peak at $\sim 4.2^{\circ}\left[d(100)^{\prime}\right]$ in the XRD spectrum. When $\mathrm{Na}$ was replaced at the same site (the $\mathrm{P} 5 \mathrm{PO}_{4}$ conjugating site of the OCP unit lattice), no significant peak shifts or extra peaks were observed and the usual OCP $d(100)$ peak appeared at $\sim 4.7^{\circ}$. By estimating these peaks in the XRD pattern, we can elucidate the $\mathrm{NH}_{4}$ substitution mechanism and the Na-exchange degree in the OCP unit lattice. Fig. 3 magnifies the XRD patterns of the samples to highlight the main peaks and Fig. 4 plots the relative peak intensity ratio of $d(100)^{\prime} /\left(d(100)^{\prime}+d(100)\right)$ versus $\mathrm{Na}$ concentration. After immersion, the intensities of the $d(100)$ peak of OCP- $\mathrm{NH}_{4}$ increased in all treated samples, indicating the development of a typical OCP unit lattice in the samples. Note that the $d(100)^{\prime} /\left(d(100)^{\prime}+d(100)\right)$ ratio of OCP- $\mathrm{NH}_{4}$ was significantly decreased even after immersion in the solution containing $0 \mathrm{~mol} \mathrm{~L}^{-1} \mathrm{Na}$. The $d(100)^{\prime} /\left[d(100)^{\prime}+d(100)\right]$ ratios in the treated samples increased with $\mathrm{Na}$ content up to $0.2 \mathrm{~mol} \mathrm{~L}^{-1}$ and then plateaued at $\sim 0.50$ until the Na concentration reached

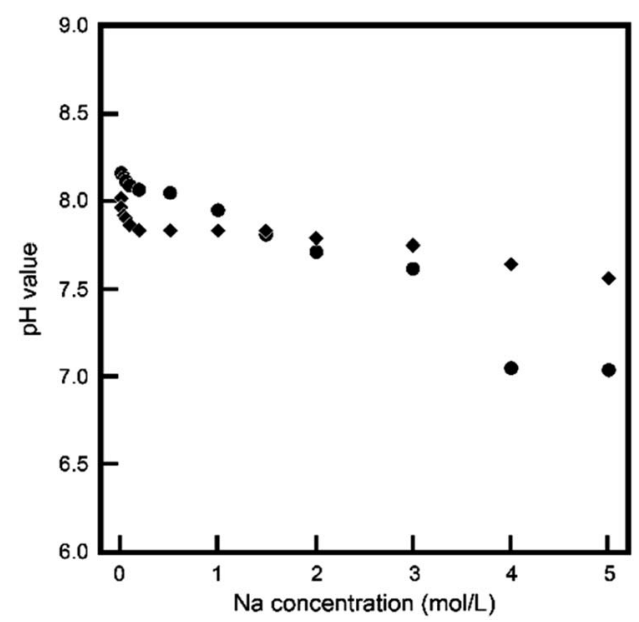

Fig. $1 \mathrm{pH}$ values of before $(\mathbf{0})$ and $\operatorname{after}(\bullet)$ of treated solutions. 


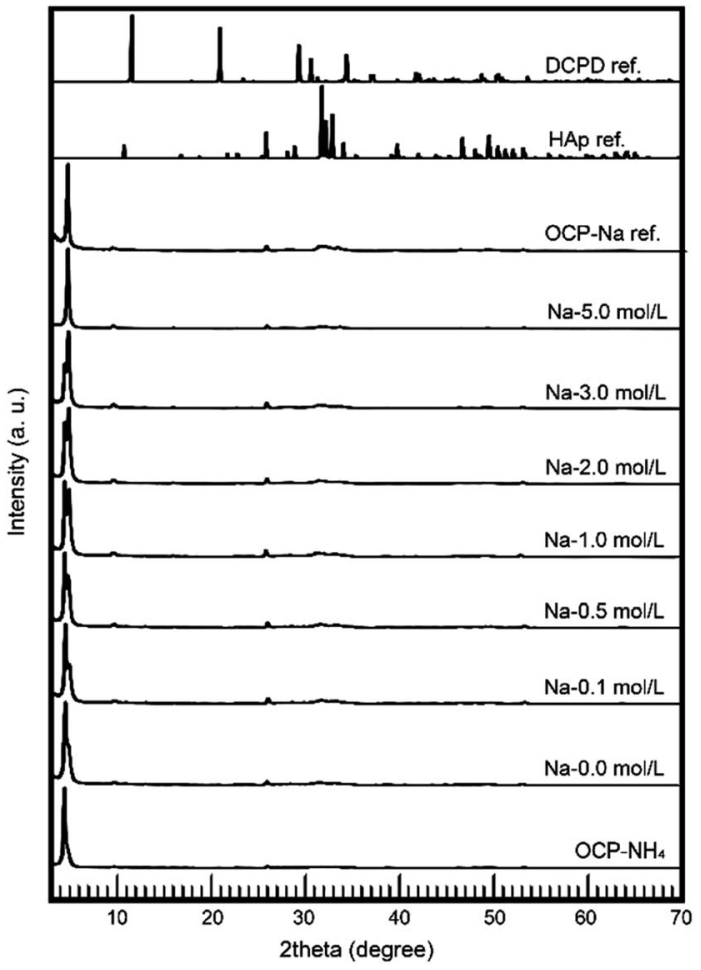

Fig. 2 Wide-range XRD patterns of treated samples.

$2.0 \mathrm{~mol} \mathrm{~L}^{-1}$. At this concentration, the $d(100)^{\prime} /\left(d(100)^{\prime}+d(100)\right)$ ratios of the treated samples began increasing again and the $d(100)^{\prime}$ peak could not be detected at $5 \mathrm{~mol} \mathrm{~L}^{-1} \mathrm{Na}$.

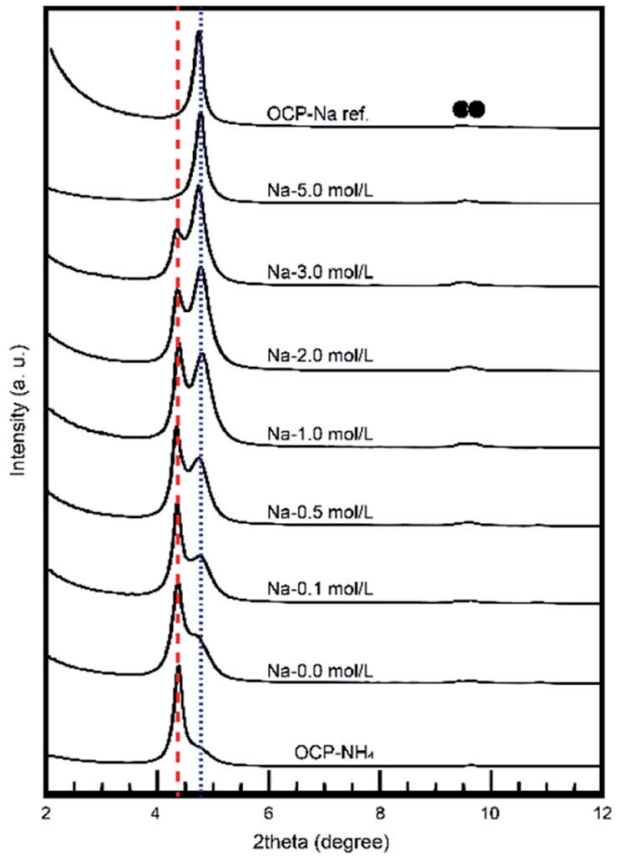

Fig. 3 Small-angle XRD patterns of treated samples. OCP, blue dot line: conventional OCP $d(100)$ and, red broken line: OCP $-\mathrm{NH}_{4} d(100)^{\prime}$.

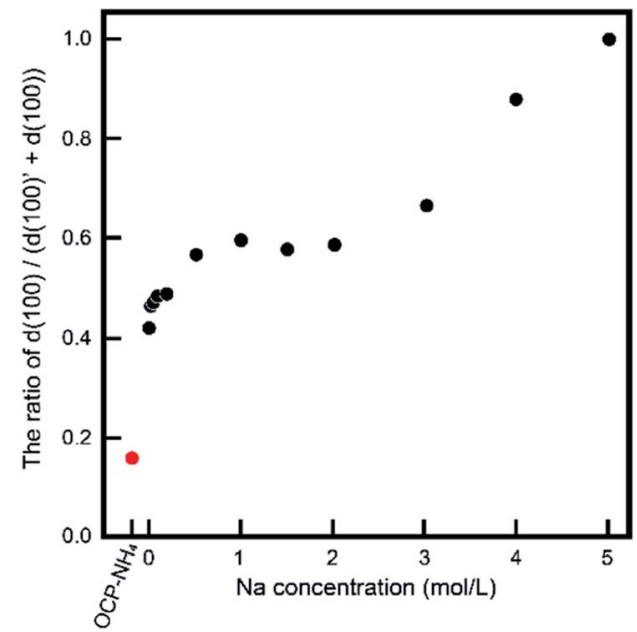

Fig. 4 Relative ratio of OCP $d(100) /\left[d(100)+d(100)^{\prime}\right]$ versus $\mathrm{Na}$ concentration in solution.

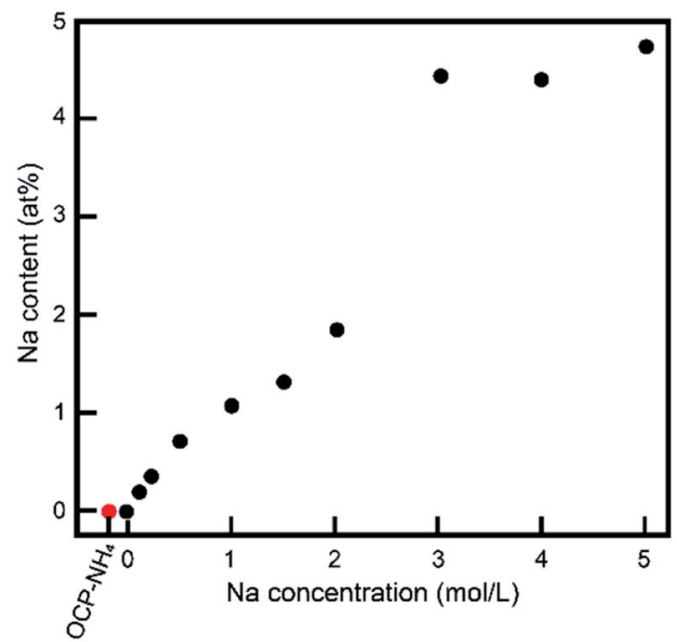

Fig. $5 \mathrm{Na}$ contents of samples as a function of $\mathrm{Na}$ concentration in solutions.

The decreased $d(100)^{\prime} /\left(d(100)^{\prime}+d(100)\right)$ ratio of OCP- $\mathrm{NH}_{4}$ in $\mathrm{Na}$-free solution was attributed to instability of $\mathrm{OCP}-\mathrm{NH}_{4}$. When OCP-NH${ }_{4}$ was immersed in different concentrations of $\left(\mathrm{NH}_{4}\right)_{2} \mathrm{HPO}_{4}$ solution $\left(0-1 \mathrm{~mol} \mathrm{~L} \mathrm{~L}^{-1}\right)$ as same manner of $1 \mathrm{~mol} \mathrm{~L}^{-1}\left(\mathrm{NH}_{4}\right)_{2} \mathrm{HPO}_{4}$ with $\mathrm{NaNO}_{3}$ solutions, its $d(100)^{\prime}$ structure gradually decomposed over time. The decomposability of the $d(100)^{\prime}$ structure of OCP-NH $\mathrm{N}_{4}$ was an inversely proportional to $\left(\mathrm{NH}_{4}\right)_{2} \mathrm{HPO}_{4}$ concentration (Fig. $\mathrm{S} 1 \dagger$ ).

The XRD measurements imply an ionic exchange of $\mathrm{NH}_{4}$ with $\mathrm{Na}$ in the OCP unit lattice. The XRD data were validated in other chemical compositional analyses. Fig. 5 shows the $\mathrm{Na}$ contents in the samples determined by ICP-OES. The Na content in the treated sample increased as the Na concentration in the treatment solution increased up to $3 \mathrm{~mol} \mathrm{~L}^{-1}$, and plateaued thereafter. We also measured the $\mathrm{Ca} / \mathrm{P}$ and $(\mathrm{Ca}+\mathrm{Na}) / \mathrm{P}$ ratios of the samples. Because the chemical composition 


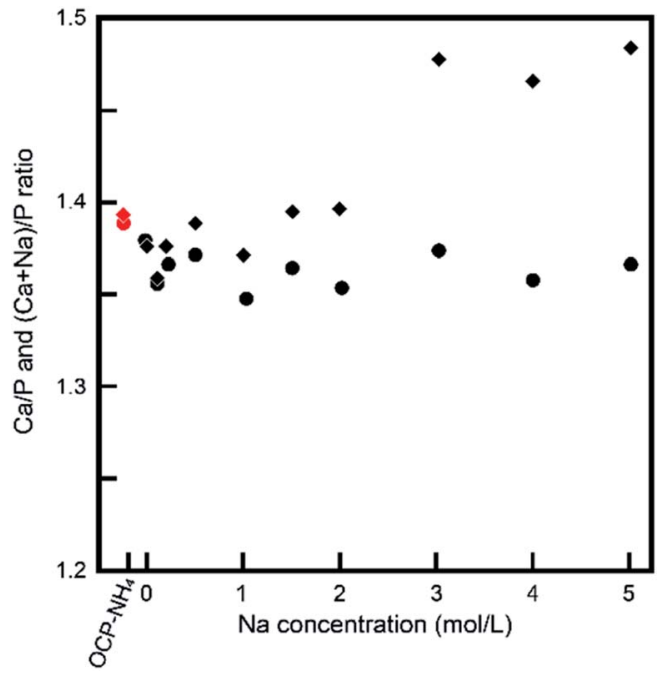

Fig. $6 \mathrm{Ca} / \mathrm{P}$ ratio $(\bullet)$ and $(\mathrm{Ca}+\mathrm{Na}) / \mathrm{P}$ ratio $(\bullet)$ of treated samples.

might alter through dissolution and/or development of OCP processes other than $\mathrm{NH}_{4}$-to- $\mathrm{Na}$ ionic exchange, these ratios provide vital information about the crystallographic alternations during treatments. Before treatment, the $\mathrm{Ca} / \mathrm{P}$ ratio of OCP-NH $\mathrm{N}_{4}$ was 1.38. Fig. 6 plots the $\mathrm{Ca} / \mathrm{P}$ and $(\mathrm{Ca}+\mathrm{Na}) / \mathrm{P}$ ratios of the samples versus Na concentration in the treatment solution. $\mathrm{The} \mathrm{Ca} / \mathrm{P}$ ratios of the treated samples trended nearly identically to those of $\mathrm{OCP}-\mathrm{NH}_{4}$, but the $(\mathrm{Ca}+\mathrm{Na}) / \mathrm{P}$ ratios steadily increased with increasing $\mathrm{Na}$ concentration in the treated solution.

The ionic-exchange process of OCP- $\mathrm{NH}_{4}$ to OCP-Na was also evaluated by the spectroscopic method. Within the lowly symmetric crystal structure of OCP $(P \overline{1})$, the vibrations of each component can be detected. ${ }^{21,22}$ The six major states of $\mathrm{PO}_{4}(\mathrm{P} 1-$
P6 $\mathrm{PO}_{4}$ ) in OCP all contain highly conjugated Ca ions. ${ }^{1523-25}$ Our previous evaluations indicated that monovalent cations such as $\mathrm{NH}_{4}$ and $\mathrm{Na}$ can be substituted at the Ca site conjugated to P5 $\mathrm{PO}_{4}$, the root of the hydrous layer. ${ }^{16,21}$ Fig. 7 shows the FT-IR spectra of the samples. Before immersion, the $\mathrm{NH}_{4}$ absorption band ranging from 1400 to $1500 \mathrm{~cm}^{-1}$ appeared in the spectrum of $\mathrm{OCP}-\mathrm{NH}_{4}$. In the treatment solutions, increasing the $\mathrm{Na}$ concentration decreased the intensity of the $\mathrm{NH}_{4}$ absorption band. Above $3 \mathrm{~mol} \mathrm{~L}^{-1} \mathrm{NaOH}$, the $\mathrm{NH}_{4}$ absorption band disappeared. This observation was consistent with the XRD analysis. However, at the $\mathrm{P}_{5} \mathrm{PO}_{4}$ site, numerous bands related to $\mathrm{Na}$ substituted OCP emerged with increasing Na concentration in the treatment solution, but the band corresponding to OCP$\mathrm{NH}_{4}$ remained visible at high $\mathrm{Na}$ concentrations.

The obtained results provided clear evidence of the ionexchange process at the $\mathrm{NH}_{4}$-substituted sites of OCP- $\mathrm{NH}_{4}$ in $\mathrm{Na}$ solution. The $\mathrm{NH}_{4}$-exchange degree of $\mathrm{OCP}-\mathrm{NH}_{4}$ was controlled by varying the $\mathrm{Na}$ concentration in the treatment solution. However, the ionic-exchange process in the OCP unit lattice required a higher $\mathrm{Na}$ concentration than direct precipitation. ${ }^{\mathbf{1 6}}$ The above chemical composition analysis indicated that the threshold value of $\mathrm{Na}$ intercalation into $\mathrm{OCP}-\mathrm{NH}_{4}$ depended on the Na concentration in solution. Below $2 \mathrm{~mol} \mathrm{~L}^{-1}$ $\mathrm{Na}$, the ion-exchange process of $\mathrm{OCP}-\mathrm{NH}_{4}$ dominated and the $d(100)^{\prime} /\left(d(100)^{\prime}+d(100)\right)$ of $\mathrm{OCP}-\mathrm{NH}_{4}$ reached $\sim 0.6$. Above $3 \mathrm{~mol} \mathrm{~L}^{-1} \mathrm{Na}$ in solution, the ionic-exchange process apparently reached the threshold in simple exchange and the Na contents in the samples no longer increased. Thus, it was suggested that $\mathrm{Na}$ adsorption simultaneously occurred on the sample surfaces with ion exchange process. It was also suggested that $\mathrm{Na}$ adsorption onto OCP- $\mathrm{NH}_{4}$ influences further ion-exchange processes. The expected exchange phenomena are summarized in Scheme 2. (a) Wide-range

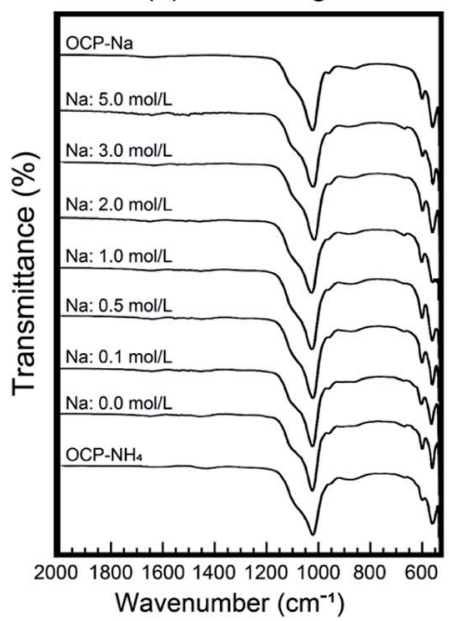

(b) $\mathrm{NH}_{4}$ adsorption

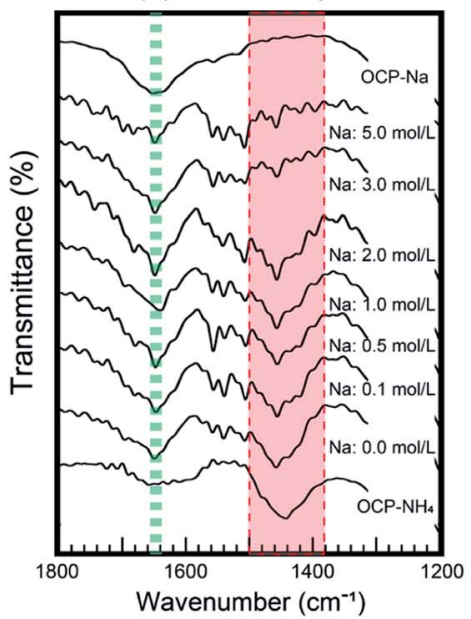

(c) $\mathrm{P5} \mathrm{PO}_{4}$

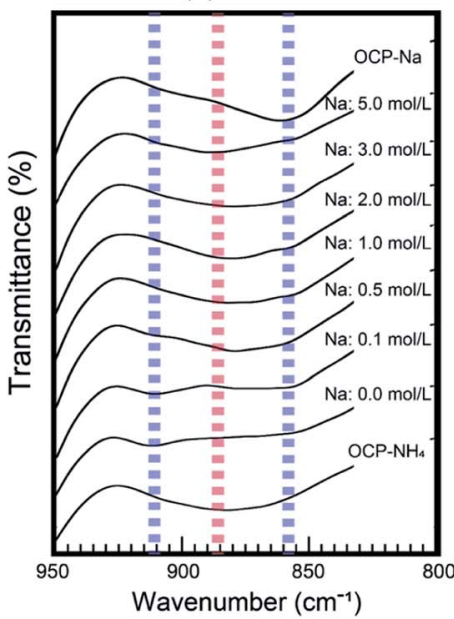

Fig. 7 FT-IR spectra of the treated samples: (a) wide-range spectra; (b) region of $\mathrm{NH}_{4}$ adsorption bands, showing the $\mathrm{HPO}_{4}$ band (green broken line) and the $\mathrm{NH}_{4}$ adsorption band (red shaded region); (c) region of $\mathrm{P} \mathrm{PO}_{4}$, showing the bands corresponding to cation adsorption of OCP-NH 4 (red broken line) and OCP-Na (blue broken lines). 

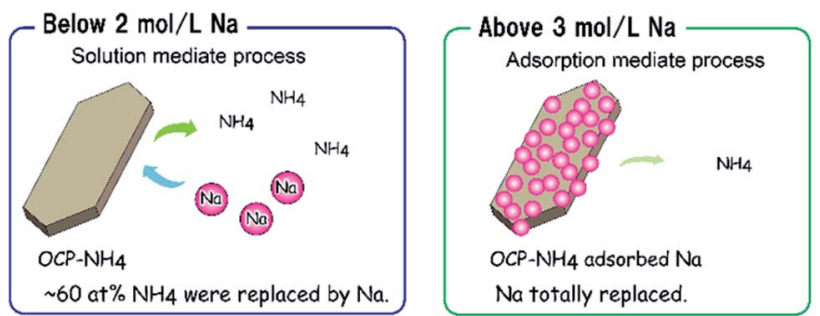

Scheme 2 Schematic of the ion-exchange process of OCP-NH $\mathrm{N}_{4}$ in systems with different $\mathrm{Na}$ concentrations.

Heretofore, although various molecules and cations can be substituted in the OCP unit lattice, ordinary ionic-exchange properties of OCP have not been reported because OCP exists in a metastable phase. ${ }^{2,26}$ However, we verified that OCP, like other layered components (clay minerals and layered double hydrates), possesses ionic-exchange properties under optimal settings. ${ }^{1-20}$ This phenomenon can be exploited in new clinical usages of OCP, especially, in combinations of medical products. For example, a controlled burst of medical drugs could be released from substituted interlayers of the OCP unit lattice.

\section{Conclusions}

We demonstrated the ionic-exchange properties of OCP in OCP$\mathrm{NH}_{4}{ }^{-}$and Na-containing solutions, which are weakly basic phosphate buffer solutions. $\mathrm{NH}_{4}$-substituted OCP was gradually replaced by $\mathrm{Na}$ as the ionic exchange proceeded. The degree of $\mathrm{Na}$ exchange was comparable with the Na concentration in the reaction solution.

\section{Conflicts of interest}

There are no conflicts to declare.

\section{Acknowledgements}

The Health Research Institute, National Institute of Advanced Industrial Science and Technology (AIST), and KAKENHI for Young Researchers, JP19K19081, funded this research. Dr Y. Suezawa and T. Nakanishi assisted with the FT-IR measurements. This study is partially supported by the Research Center for Industrial Science \& Technology, Kagawa Industry Support Foundation (RIST Kagawa).

\section{Notes and references}

1 E. Davies, K. H. Müller, W. C. Wong, C. J. Pickard, D. G. Reid, J. N. Skepper and M. J. Duer, Proc. Natl. Acad. Sci. U. S. A., 2014, E1354.

2 L. Wang and G. H. Nancollas, Chem. Rev., 2008, 108, 4628.

3 S. V. Dorozhkin and M. Epple, Angew. Chem., Int. Ed., 2002, 41, 3130 .

4 M. Markovic, B. O. Fowler and W. E. Brown, Chem. Mater., 1993, 5, 1401.

5 T. Yokoi, M. Kamitakahara and C. Ohtsuki, Dalton Trans., 2015, 44, 7943.

6 H. Monma and M. Goto, Bull. Chem. Soc. Jpn., 1983, 56, 3843.

7 T. W. T. Tsai, F. C. Chou, Y. H. Tseng and J. C. C. Chan, Phys. Chem. Chem. Phys., 2010, 12, 6692.

8 S. Kamakura, Y. Sasano, T. Shimizu, K. Hatori, O. Suzuki, M. Kagayama and K. Motegi, J. Biomed. Mater. Res., 2002, 59, 29.

9 A. Bigi, E. Boanini, B. Bracci, G. Falini and K. Rubini, J. Inorg. Biochem., 2003, 95, 291.

10 E. Boanini, M. Gazzano, K. Rubini and A. Bigi, Cryst. Growth Des., 2010, 10, 3612.

11 H. Shi, F. He and J. Ye, J. Mater. Chem. B, 2016, 4, 1712.

12 Y. Sugiura and Y. Makita, Chem. Lett., 2019, 48, 1304.

13 I. Yamada and M. Tagaya, Colloid Interface Sci. Commun., 2019, 30, 100182.

14 Y. Sugiura, Y. Saito, T. Endo and Y. Makita, Cryst. Growth Des., 2019, 19, 4162.

15 Y. Sugiura and Y. Makita, Cryst. Growth Des., 2018, 18, 6165. 16 Y. Sugiura and Y. Makita, Dalton Trans., 2019, 48, 1386.

17 R. Zhu, Q. Chen, Q. Zhou, Y. Xi, J. Zhu and H. He, Appl. Clay Sci., 2016, 123, 239.

18 T. Okumura, K. Tamura, E. Fujii, H. Yamada and T. Kogure, Microscopy, 2014, 63, 65.

19 G. M. Bowers, D. L. Bish and R. J. Kirkpatrick, Langmuir, 2008, 24, 10240.

20 K. Matsuo, K. Yoshihara, N. Nagaoka, Y. Makita, H. Obika, T. Okihara, A. Matsukawa, Y. Yoshida and B. V. Meerbeek, Acta Biomater., 2019, 100, 388.

21 Y. Sugiura and Y. Makita, Chem. Lett., 2018, 47, 1371.

22 E. E. Berry and C. B. Baddiel, Spectrochim. Acta, Part A, 1967, 23, 1781.

23 W. E. Brown, J. P. Smith, J. R. Lehr and A. W. Frazier, Nature, 1962, 196, 1050.

24 M. Mathew and W. E. Brown, Bull. Chem. Soc. Jpn., 1987, 60, 1141.

25 M. Mathew, W. E. Brown, L. W. Schroeder and B. Dickens, J. Crystallogr. Spectrosc. Res., 1988, 18, 235.

26 G. Vereecke and J. Lemaitre, J. Cryst. Growth, 1990, 194, 820. 